\title{
Effect of waste ceramic adsorbent on wastewater treatment
}

\author{
Yao Zheng*, Qun Yuan, ZiYing Yan, Jiacheng Liu, Jingying Liang, Linjiang He, Jianjun He, Min Yan, L He \\ School of Environmental andChemical Engineering, Foshan University, Foshan, China
}

\begin{abstract}
The preparation of porous ceramic with waste porcelain powder as aggregate research. The influence of the amount of Sesbania powder and the calcination temperature on the adsorption performance of porous ceramics was investigated. The effect of the amount of porous ceramic and the adsorption time on the removal rate of $\mathrm{Cu}$ in wastewater containing $\mathrm{Cu}$ was investigated.The results showed that the adsorption properties of porous ceramics were related to the calcination temperature and the amount of Sesbania powder. The suitable calcination temperature and the amount of Sesbania powder were $600{ }^{\circ} \mathrm{Cand} 4 \mathrm{wt} \%$, respectively.The removal rate of $\mathrm{Cu}$ in water samples increases with the increase of the amount of porous ceramics and the increase of adsorption time. The suitable amount of porous ceramics is $10 \mathrm{~g} / \mathrm{L}$ and the adsorption time is $35 \mathrm{~min}$. XRD characterization showed that the crystal particles were grown by calcination, and the properties of porous ceramics were stable before and after adsorption.
\end{abstract}

\section{Introduction}

Since the reform and opening to the outside world, China's ceramic industry has been developing by leaps and bounds, especially the ceramic industry in Guangdong. In 2015, the output of industrial ceramics in Guangdong accounted for about $30 \%$ of the world's total, accounting for more than $60 \%$ of the total, of which nearly $70 \%$ of exports, and the annual rate of $30 \%$ growth. However, with the rapid development of ceramic industry, ceramic industry waste generated is also increasing, it not only caused great pressure on the environment, but also restricts the sustainable development of the ceramic industry, and many of the waste ceramic components can not be reasonably utilized, resulting in a waste of resources two. At present, China's ceramic industry waste treatment and utilization is relatively low, a large number of waste land crowding, so that water and air are seriously polluted. Therefore, with the gradual attention of the society to environmental protection work, the treatment and comprehensive utilization of waste materials in ceramic industry has become a common concern of the ceramic industry and environmental protection departments.

The adsorption method is used to treat wastewater containing heavy metal ions, and activated carbon is usually used as adsorbent. Because the activated carbon has a strong adsorption capacity, high removal efficiency, but the price is expensive, the application subject to certain restrictions, but the ceramic industry waste ceramics for daily use, the original clay composition is kaolin, which is suitable for used as adsorption medium in water treatment. The waste domestic ceramics are re sintered into porous ceramic [4-5] by adding pores, adhesives and other materials. Because of its internal porous, large specific surface area, good chemical and thermal stability, it has better adsorption properties, and this porous ceramic is easy to regenerate, easy to reuse [6-7]. This shows that waste ceramics in wastewater treatment has a wide range of applications and development of space [8-13].In this paper, the treatment of $\mathrm{Cu}$ containing wastewater by fired porous ceramics is studied.

\section{Experiment}

\subsection{Experimental reagents, materials, instruments and equipment}

The Experimental reagent: $\mathrm{Cu}\left(\mathrm{NO}_{3}\right), \mathrm{CuCl}_{2}, \mathrm{HCL}, \mathrm{HNO}_{3}$, $\mathrm{NaOH}$, they are both analytical pure, and the manufacturers are Guangzhou Chemical Reagent Co., ltd..Experimental material: Sesbania powder, replaced by starch in the supermarket. Clay: Chaozhou porcelain factory. Discarded ceramics for daily useExperimental instruments and equipment: ball mill pulverizer, electronic analytical balance, $\mathrm{pH}$ meter, air bath thermostats oscillator, digital electric thermostatic drier, muffle furnace,type 4510 atomic absorption spectrophotometer (Shanghai precision scientific instrument factory).

\subsection{Analysis method}

Although the porous ceramic with water treatment can be naturally settled, in order to save time, the water samples are separated and separated by centrifugal separator for digestion and detection. The $\mathrm{pH}$ values of water samples are measured with a $\mathrm{pH}$ meter. The concentration of $\mathrm{Cu}$ ion in raw water and treated effluent was determined by 
atomic absorption spectrophotometer. The properties of raw porcelain powder and samples before and after adsorption were examined by $\mathrm{X}$ ray diffractometer.

\section{Experimental results and discussion}

\subsection{Preparation and selection of porous ceramics}

The experiment used the waste daily ceramic powder with a quality amount of $50 \mathrm{wt} \%$.With $2 \mathrm{wt} \%, 4 \mathrm{wt} \%$, 6 wt $\%, 8$ wt $\%$ of sesbania powder, a percentage of China clay powder, mixed into circular block body, keep calibration of the sample after, to be put in the oven at $105{ }^{\circ} \mathrm{C}$ drying, and then in the muffle furnace at $600{ }^{\circ} \mathrm{C}$, respectively, $800{ }^{\circ} \mathrm{C}, 1000{ }^{\circ} \mathrm{C}$ calcination $5 \mathrm{~h}$ shape.The serial number of porous ceramics prepared under different conditions is listed as follows:

Table 1 Porous ceramics prepared in different conditions

\begin{tabular}{|c|c|c|c|c|}
\hline $\begin{array}{r}\text { Seshania powder dosage } \\
\text { Calcination temperature }\end{array}$ & $2 \mathrm{wt} \%$ & $4 \mathrm{wt} \%$ & $\begin{array}{c}6 \\
\mathrm{wt} \%\end{array}$ & $\begin{array}{c}8 \\
\mathrm{wt} \%\end{array}$ \\
\hline $600^{\circ} \mathrm{C}$ & $\# 1$ & $\# 2$ & $\# 3$ & $\# 4$ \\
\hline $800^{\circ} \mathrm{C}$ & $\# 5$ & $\# 6$ & $\# 4$ & $\# 8$ \\
\hline $1000^{\circ} \mathrm{C}$ & $\# 9$ & $\# 10$ & $\# 11$ & $\# 12$ \\
\hline
\end{tabular}

Experimental methods:(1)Crush samples and screen them by 100 mesh screen.(2)Take $50 \mathrm{mg} / \mathrm{L} \mathrm{Cu}$ containing water sample (instead of $\mathrm{Cu}$ containing wastewater) $100 \mathrm{~mL}$ in $250 \mathrm{~mL}$ conical flask, add $2 \mathrm{~g}$ porous ceramic powder, oscillate $90 \mathrm{~min}$ on the oscillator, and place it slightly, centrifugal separation. The amount of residual $\mathrm{Cu}$ wasdetermined by proper supernatant, and the removal rate of $\mathrm{Cu}$ was calculated according to the following formula: $\mathrm{Cu}$ removal rate $=(\mathrm{C} 0-\mathrm{C}) / \mathrm{C} 0 \times 100 \%$ In formula: $\mathrm{C} 0-\mathrm{Cu}^{2+}$ concentration in $\mathrm{Cu}$ bearing water samples,mg/L.C - after treatment, the $\mathrm{Cu}^{2+}$ concentration of water samples, $\mathrm{mg} / \mathrm{L}$.

Table 2 Adsorption effect of porous ceramics

\begin{tabular}{|c|c|c|c|c|c|c|c|c|c|c|c|c|c|}
\hline Sample & $\begin{array}{c}\# 0 \\
\text { porce } \\
\text { lain }\end{array}$ & $\# 1$ & $\# 2$ & $\begin{array}{l}\# \\
3\end{array}$ & $\begin{array}{l}\# \\
4\end{array}$ & $\begin{array}{l}\# \\
5\end{array}$ & $\begin{array}{l}\# \\
6\end{array}$ & $\begin{array}{l}\# \\
7\end{array}$ & $\begin{array}{l}\# \\
8\end{array}$ & $\begin{array}{l}\# \\
9\end{array}$ & $\begin{array}{c}\# \\
10\end{array}$ & $\begin{array}{c}\# \\
11\end{array}$ & $\begin{array}{c}\# \\
12\end{array}$ \\
\hline $\begin{array}{l}\text { Concentration of } \mathrm{Cu} \\
\text { after adsorption/ } \mathrm{mg} / \mathrm{L}\end{array}$ & 16.2 & 10.8 & $\begin{array}{c}5.1 \\
6\end{array}$ & 8.80 & 8.26 & 7.72 & 7.82 & 8.26 & 8.9 & 9.3 & 8.5 & 8.8 & 10.2 \\
\hline
\end{tabular}

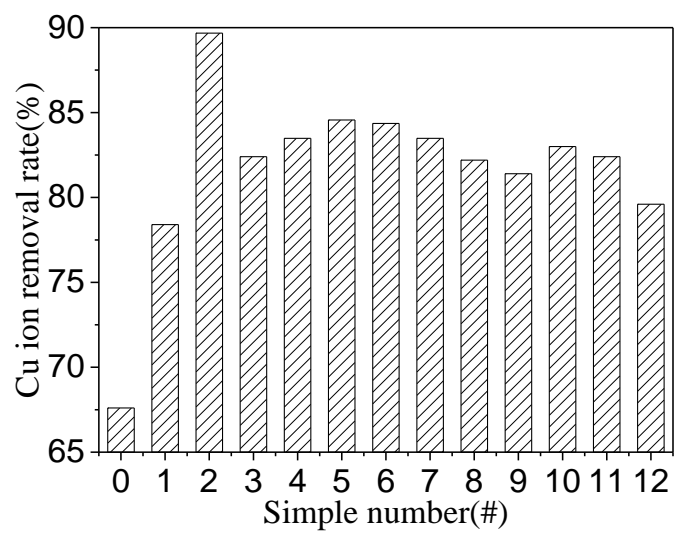

Fig. 1 Adsorption effect of porous ceramic sample on $\mathrm{Cu}$

From Sesbania powder mixture on the dosage, moderate dosage can produce more porous channel and surface area, is conducive to the adsorption of metal ions to a certain temperature; roasting, baking to make ceramic porosity increases, so as to enhance the adsorption effect, but if the calcination temperature is too high, the surface will form a sintered ceramic sample that is not conducive to the porosity and the specific surface area increased.From the above Table 2 and Fig. 1 shows that the porous ceramic samples of \#2 containing $4 \mathrm{wt} \%$ Sesbania powder calcined at $600{ }^{\circ} \mathrm{C}$ for molding, the best adsorption of simulated wastewater containing $\mathrm{Cu}$, the removal rate of $\mathrm{Cu}^{2+}$ reached $89.68 \%$, the relative waste porcelain powder on the removal rate of $\mathrm{Cu}^{2+}$ is higher 
than 22.08 percentage points, so the best of porous ceramics, the next step adsorption experiment.

\subsection{The influence of the amount of porous ceramic on the removal rate of $\mathrm{Cu}$}

\#2 porous ceramics determined by the above experiments were selected,That is, it prepared by calcination of $4 \mathrm{wt} \%$ Sesbania powder at $600{ }^{\circ} \mathrm{C}$. The weighing of porous ceramic powder were $2 \mathrm{~g} / \mathrm{L}, 4 \mathrm{~g} / \mathrm{L}, 6 \mathrm{~g} / \mathrm{L}, 8 \mathrm{~g} / \mathrm{L}, 10 \mathrm{~g} / \mathrm{L}$, $12 \mathrm{~g} / \mathrm{L}, 14 \mathrm{~g} / \mathrm{L}, 16 \mathrm{~g} / \mathrm{L}, 18 \mathrm{~g} / \mathrm{L}$, on the concentration of 25 $\mathrm{mg} / \mathrm{L}$ (the $\mathrm{pH}$ test is neutral) containing $\mathrm{Cu}$ solution of oscillating adsorption, with $100 \mathrm{~mL}$ of water with $\mathrm{Cu}$,explore the optimal dosage of porous ceramics. The oscillation adsorption in this series is $90 \mathrm{~min}$, and the experimental results are shown in Table 3 and figure 2:

Table 3 Effect of the amount of porous ceramic on the removal rate of $\mathrm{Cu}$

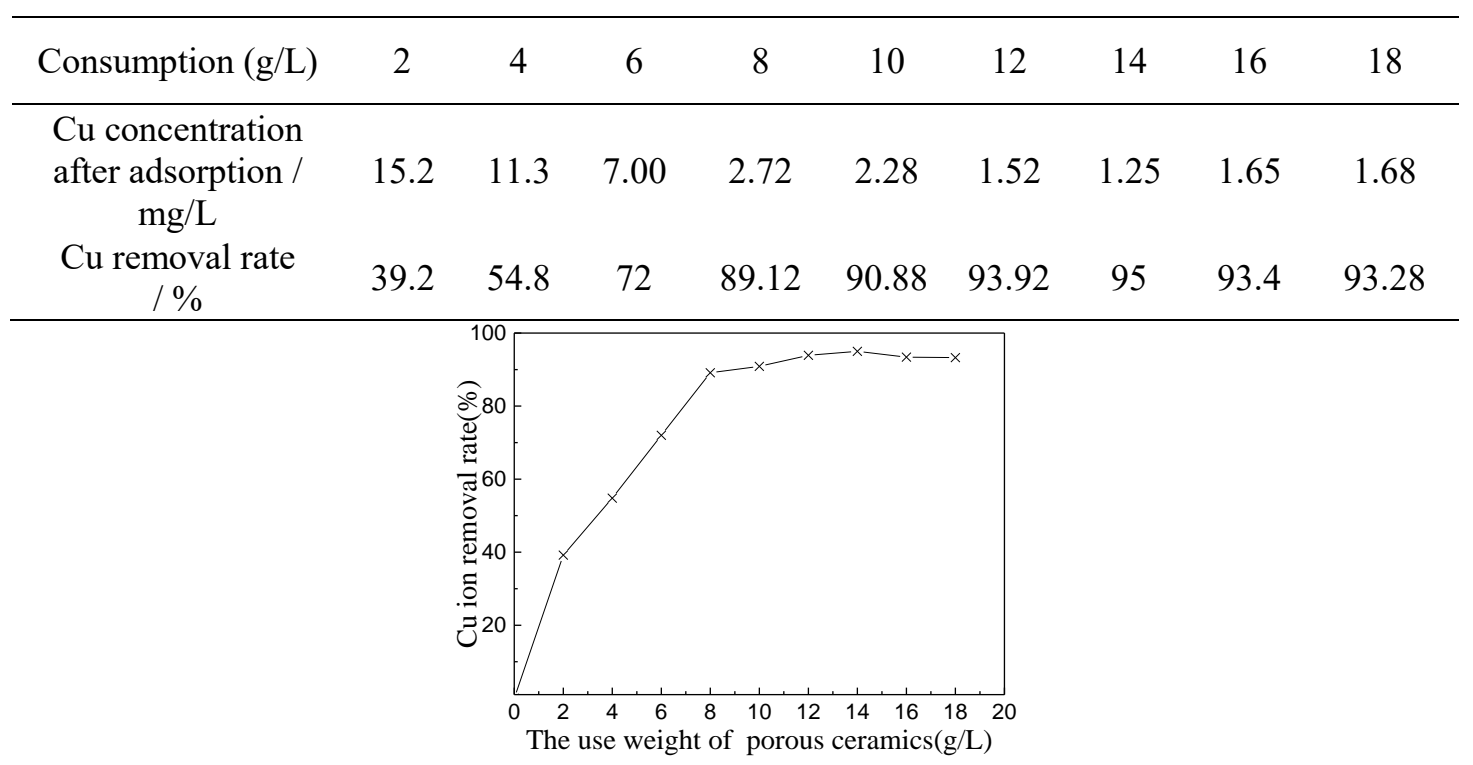

Fig. 2 Effect of the amount of porous ceramic on the removal rate of $\mathrm{Cu}$

From table 3 and Figure 2, it is found that the removal rate of $\mathrm{Cu}$ increases rapidly with the increase of the amount of porous ceramics. However, when the amount of porous ceramic reaches $10 \mathrm{~g} / \mathrm{L}$, the removal rate of $\mathrm{Cu}$ in water samples tends to be mild, and the removal rate of $\mathrm{Cu}$ reaches saturation at $90.88 \%$. In order to ensure better treatment effect of wastewater and save the amount of porous ceramics, the amount of porous ceramic was chosen as $10 \mathrm{~g} / \mathrm{L}$ to treat wastewater containing $\mathrm{Cu}$.

\section{Conclusions}

(1) Using the waste ceramics from the ceramics factory as the raw material to produce porous ceramics, the utilization rate of waste is high, and the social and economic benefits are good.

(2) The adsorption properties of porous ceramics are related to the calcination temperature and the amount of doped Sesbania powder. The suitable calcination temperature and the amount of doped Sesbania powder can greatly improve the adsorption efficiency of porous ceramics.

(3) At the baking temperature of $600{ }^{\circ}$ Cand the dosage of $4 \mathrm{wt} \%$ Sesbania powder, the porous ceramic with the highest cost performance ratio.

\section{Acknowledgments:}

This work was supported by Water Pollution Control Engineering Technology Research Center of Foshan(2016GA10159), 2016 Foshan Science and Technology Project.

\section{References}

1. Fuxin Han. Study on the production of porous ceramics from waste materials of ceramics factory $[\mathrm{J}]$ ceramics research, 2002, 35 (1): 24-27.

2. Dongmei Wan, Gang Peng. The research development of solid waste ceramic concrete materials [J]. Foshan ceramics, 2001, 10 (1): 4-6.

3. ThomasPumpelLynneE.Maeaskie,JohnA.Finlay,Lud oDielsandMariosTsezos;Cuckel Removal form Cuekel Plating waste water using a biologically aetive moving -bed sand filter:BioMetals,2003,16:567-581.

4. $\mathrm{Vu} \mathrm{D} \mathrm{H}$, Wang K S, Bac B H. Humidity control porous ceramics prepared from waste and porous materials[J]. Materials Letters, 2011, 65(6):940-943.

5. Vu D H, Wang K S, Nam B X, et al. Preparation of humidity-controlling porous ceramics from volcanic ash and waste glass[J]. Ceramics International, 2011, 
37(7):2845-2853.

6. Dousova B, Kolousek D, Keppert M, et al. Use of waste ceramics in adsorption technologies[J]. Applied Clay Science, 2016.

7. Zhang Y L, Wang C Z, Shi C, et al. [Preparation of porous ceramics based on waste ceramics and its $\mathrm{Ni} 2+$ adsorption characteristics][J]. Environmental Science, 2013, 34(7):2694.

8. GS.lonsdon;Eeffetivemanagementandoperationofeoa gulationandfiltration; Water,Air,and Pollution1,2000,23(2):159-166.

9. Fangling Jian, Shilong Wang, Hong Zhang, et al,Treatment of Zinc containing wastewater with ceramisite $[\mathrm{J}]$.Chemical propellants and polymeric materials,2002,12(3):31-34

10. Kawase M. High-concentration waste water treatment by anaerobic fixed bed filled with porous ceramics.[J]. J.env.cons.eng, 1987, 16:497-501.

11. Fernandes R S, De Campos É, Minatti J L, et al. Alumina Porous Ceramics: Mathematical Behavior at Different Commercial Starch Concentration[J]. 2008, 591-593:442-447.

12. Liu T. Analysis of the development of porous ceramic and its performance in the Sewage Treatment[J]. Advanced Ceramics, 2013.

13. Liu S Y, Yang Y M, Liu Q. Porous ceramic material and its applications in environmental engineering $[\mathrm{J}]$. Journal of University of Jinan, 2008. 